\title{
What Kind of Charging Infrastructure Do Chevrolet Volt Drivers in The EV Project Use and When Do They Use It?
}

Shawn Salisbury

September 2014

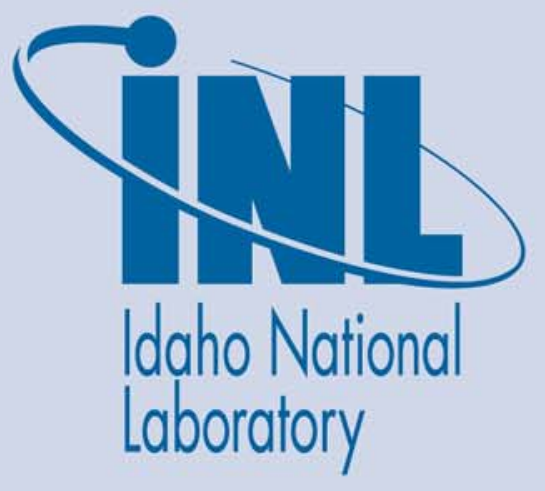

The INL is a U.S. Department of Energy National Laboratory operated by Battelle Energy Alliance 


\title{
What Kind of Charging Infrastructure Do Chevrolet Volt Drivers in The EV Project Use and When Do They Use It?
}

\author{
Shawn Salisbury
}

September 2014

\author{
Idaho National Laboratory \\ Idaho Falls, Idaho 83415
}

http://www.inl.gov

Prepared for the

U.S. Department of Energy

Office of Energy Efficiency and Renewable Energy

Under DOE Idaho Operations Office

Contract DE-AC07-05ID14517 
What Kind of Charging Infrastructure Do Chevrolet Volt Drivers in The EV Project Use and When Do They Use It?

September 2014

\section{Key Conclusions}

- A sample of 1,867 Chevrolet Volt drivers participating in The EV Project performed $87 \%$ of their charging events at home and $13 \%$ away from home over a 15-month study period.

- Although the majority (i.e., $59 \%$ ) of all charging events were performed at home overnight, $28 \%$ of all events were performed at home during the day. Only $12 \%$ of charging events were performed away from home during the day. The fact that $70 \%$ of daytime charging was performed at home is significant, because typically daytime "opportunity" charging has been thought of as away-from-home charging.

- All vehicles in this study had access to AC Level 2 $(240-\mathrm{V})$ charging at home; therefore, it is not surprising that nearly all home charging was conducted using Level 2 charging equipment. Away-from-home charging was split evenly between Level 2 charging units and AC Level $1(120-V)$ charging units or standard 120-volt outlets.

- Not everyone used away-from-home charging infrastructure equally. In fact, three quarters of the away-from-home charging was performed by $20 \%$ of the vehicles. A small portion of vehicles (i.e., $5 \%$ ) were never charged away from home.

- Drivers who performed 30 to $60 \%$ of their charging events away from home tended to supplement daily home charging with regular away-from-home charging. All together, these drivers averaged 2.0 charges per day. Frequent charging allowed them to average 40.3 miles driven in electric vehicle (EV) mode per day, which is a $60 \%$ increase in daily EV miles over the group of vehicles that never charged away from home.

- Drivers who charged away from home for more than $60 \%$ of their charging events tended to supplement frequent away-from-home charging with home charging. Their away-from-home charging frequency was the same as the home charging frequency of the group of drivers that never charged away from home.

- Across all of the away-from-home charging frequency groups, groups averaged 74 to $80 \%$ of their distance driven in EV mode. Overall average charging frequency increased as average daily distance driven increased, suggesting that drivers changed their charging behavior in order to extend EV mode operation.

\section{Which Vehicles are Being Studied?}

Over 2,000 private owners of Chevrolet Volts in 18 metropolitan areas across the United States participated in The EV Project. They agreed to allow project researchers to monitor the usage of their vehicles throughout the project. Data collected between October 1, 2012, and December 31, 2013 (i.e., the end of EV Project data collection) from a sample of 1,867 participating Volts were analyzed to determine how these vehicles were used. This set of vehicles drove more than 20 million miles and performed over 763,000 charging events in the 15-month study period. Appendix A shows how these vehicles were distributed across the 18 metropolitan areas in The EV Project that included Volts. On average, these vehicles drove 40.0 miles per day, 29.9 of which were in EV mode, and charged 1.5 times per day on days when the vehicle was driven.

\section{What Kind of Charging Infrastructure Did the Vehicles Use and When Did They Use It?}

Volt owners have a number of options for charging their vehicles' batteries. The Chevrolet Volt is capable of charging at both AC Level $1(120-\mathrm{V})$ and AC Level 2 (240-V) charge rates. Each Volt comes with a Level 1 cordset that can be plugged into almost any 120 -volt outlet. The Volt can also be charged using any Level 2 charging unit equipped with a Society of Automotive Engineers J1772-compliant connector. Each EV Project participant had such a Level 2 charging unit installed at their home.

Charging events from the 1,867 vehicles studied were identified and categorized by location, charge power level, and time of day. For each charging event, the vehicle's charge location was classified as either at home (meaning at the vehicle owner's primary residence) or away from home. Most charging events were categorized as either Level 1 or Level 2. The power level of some events could not be determined due to incomplete data. Finally, charging events were categorized by time of day. A charge occurred during the daytime if it occurred between the vehicle's first and last trips of the day. A charge was classified as an overnight charge if it occurred after the vehicle's last trip of the day. For this analysis, a day begins and ends at 4 a.m. The overall split of the 763,002 charges by location and power level is shown in Figure .

It is apparent that the majority of the charging events occurred at home, accounting for $87 \%$ of all charges. Level 2 home charging made up at least $73 \%$ of all charging events, with home overnight Level 2 charges accounting for $49 \%$ of all charges and home daytime Level 2 charges accounting for $24 \%$ of all charging events. 


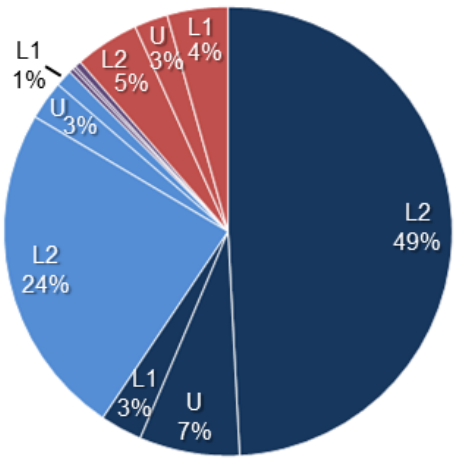

- Home Overnight

- Home Daytime

- Away Overnight*

-Away Daytime

* $1 \%$ of all charge events

Figure 1. Percent of charging events performed by location, power level, and time of day. L2 refers to Level 2 charges, L1 refers to Level 1, and $U$ refers to charges of an unknown power level.

There were instances of drivers using Level 1 charging at home both during the day and overnight; however, these cases were relatively infrequent and accounted for only $4 \%$ of all charges. This is reasonable considering that Level 2 charging units were available at each vehicle's home location. Away-from-home charging occurred almost exclusively during the daytime. Level 1 charges were performed about as frequently as Level 2 charges when away from home. Very few (i.e., 1\%) of away-from-home charges occurred overnight at any level.

Of all events, $28 \%$ were performed at home during the day. Only $12 \%$ of charging events were performed away from home during the day. Daytime charging typically has been thought of as being performed away from home. However, drivers of the vehicles in this study performed $70 \%$ of daytime charging events at home. They found an opportunity to return home during the day and favored charging there over charging away from home during the daytime.

Figure 2 shows the amount of charging energy consumed by vehicles during charging events described in Figure 1.

The proportion of energy charged at home versus away from home was similar to the percentage of charging events performed in each, with $90 \%$ of energy consumed at home and $10 \%$ of energy consumed away from home. At home, the major differences between charge frequency and energy were seen between daytime and overnight charging. Overnight home charging accounted for much more of the energy charged than daytime home charging. This is consistent with the traditional expectation that most of a vehicle's charging energy can be provided by long overnight charging events at home.

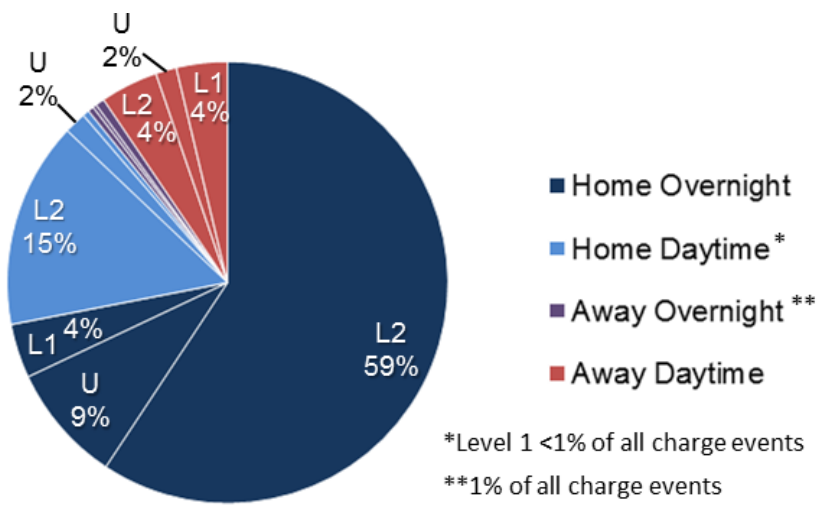

Figure 2. Percent of energy charged by location, power level, and time of day. L2 refers to Level 2 charges, L1 refers to Level 1, and $U$ refers to charges of an unknown power level.

Away-from-home daytime charging consumed a greater percentage of energy than home daytime charging. This suggests that, during the day, drivers were somewhat more likely to be charging away from home for longer periods of time than when at home. This is probably due to the influence of workplace charging, where vehicles tend to stay plugged in for many hours. At least a portion of drivers in this study had regular access to workplace charging, but it is not known exactly how many. Charging and driving behavior of a subset of Leafs in this data set whose drivers are known to have had access to workplace charging is discussed in other papers [1].

When charging away from home, the percent of energy charged at Level 1 and Level 2 was similar to the percent of charge events performed at each power level. This means that the energy charged per away-from-home charging event was nearly equal for Level 1 and Level 2 charging events, even though Level 1 charging occurs at half the power of Level 2 . This fact is particularly significant for away-from-home charging, where daytime "opportunity" charge time is typically expected to be short. This is consistent with the assumption that charging away from home was conducted at locations where the vehicle was parked for long periods of time, such as at work.

\section{How Did Infrastructure Usage Vary from Vehicle to Vehicle?}

To understand drivers' usage of away-from-home charging infrastructure, data were analyzed on a per-vehicle basis. First, the relative contribution of away-from-home charging events for each vehicle was calculated. It was determined that $20 \%$ of vehicles with the most away-from-home charging performed $76 \%$ of all away-from-home charges. This indicates that drivers did not uniformly utilize awayfrom-home charging infrastructure, but rather a minority of drivers were the predominant users. 
To explore this idea further, vehicles were grouped based on how much away-from-home charging they performed relative to home charging. The percent of vehicles in each group is plotted in Figure 3.

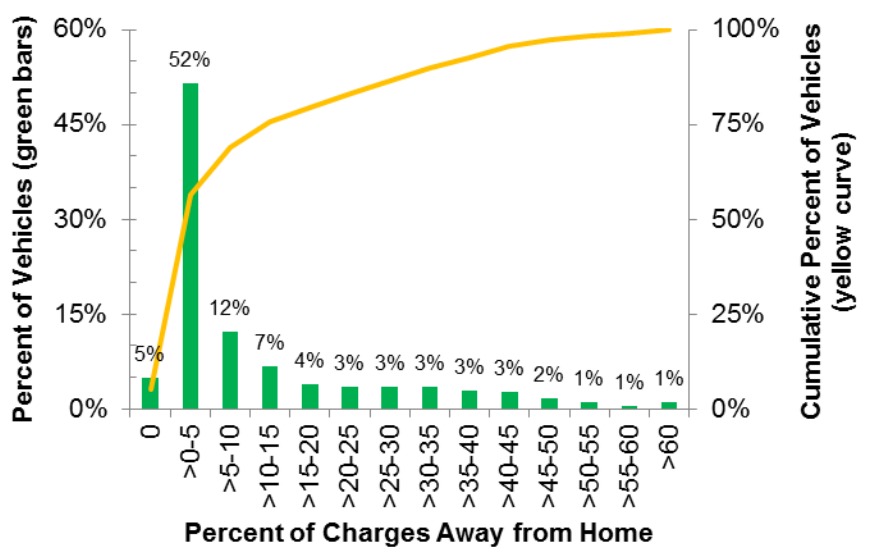

Figure 3. Distribution of the percent of charges performed away from home by each vehicle.

Figure 3 shows that $57 \%$ of the vehicles studied performed $5 \%$ or fewer of their charging events away from their home locations and $5 \%$ of vehicles had zero away-from-home charges. On the other hand, some vehicles did most of their charging away from home and a few charged away from home $100 \%$ of the time.

Away-from-home charging can be either Level 1 or Level 2; therefore, breaking down away-from-home charges by power level is important to further understand drivers' charging habits. Figure 4 shows the percentage of charges at each power level performed by the vehicles in the groups defined in Figure 3.

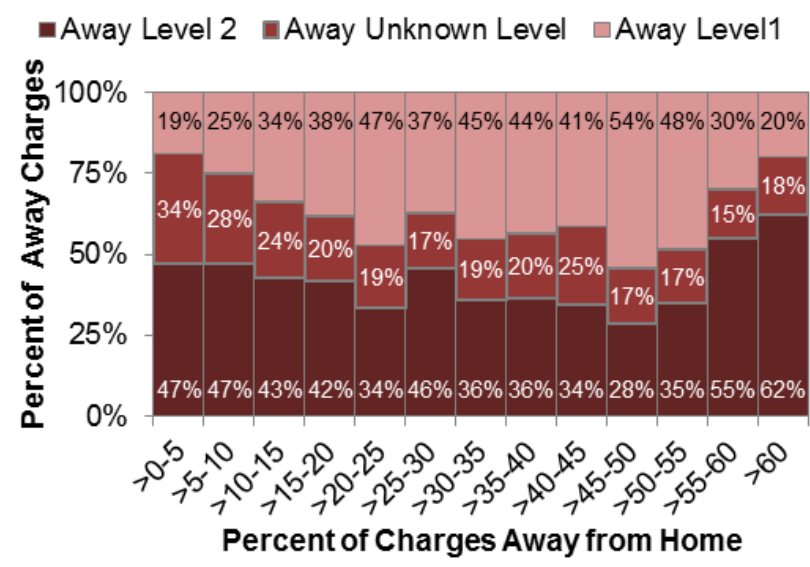

Figure 4. Occurrence of Level 1 and Level 2 charging for groups of vehicles with different amounts of away-fromhome charging.
Overall, away-from-home charging was split roughly in half between Level 1 and Level 2 . While it is difficult to quantify exactly because of the number of events with an indeterminate power level, it appears that drivers who performed about a third to half of their charging away from home slightly favored Level 1 charging. However, the sample size of each of these groups is relatively small (as shown in Figure 3); therefore, this result may be skewed by atypical charging habits of just a few vehicles in these groups.

\section{Did Away-from-Home Charging Enable Increased Driving in EV Mode?}

The vehicles grouped by the percent of charges away from home were analyzed to identify any differences in overall charging and driving behavior. Several metrics were calculated for each group and have been consolidated into four groups. These metrics are presented in Table 1.

Home overnight charging was quite similar for the groups with $60 \%$ or fewer of their charges away from home. They all averaged slightly less than one charge per day with an average state of charge (SOC) increase of about $65 \%$ of the battery's capacity per charge. Those that charged away from home more than $60 \%$ of the time only charged at home overnight 0.3 times per day and received an average SOC increase of $56 \%$ per charge.

All groups averaged 0.3 to 0.4 home daytime charges per day, except those charging away from home more than $60 \%$ of the time, who averaged just 0.1 . All groups had an average SOC increase for home daytime charging of around $33 \%$ of the battery's capacity, roughly half the increase of overnight charging for the same groups. This reinforces the observation made previously that Volt drivers used their home charging units to perform daytime "opportunity" charging.

Away-from-home overnight charging occurred very infrequently (i.e., the average charges per day for all groups rounded to 0.0 ). When drivers found the rare opportunity to charge overnight when they were not at home, the SOC increase from these charges was on the same order as those that occurred overnight at home.

When charging away from home during the daytime, drivers most likely used publicly accessible and/or workplace charging infrastructure, the group with 0 to $30 \%$ of their charges away from home occasionally charged away from home during the daytime, averaging 0.1 charges per day with an SOC increase of $40 \%$ per charge. The two groups with more away-from-home charging charged during the daytime away from home about once per day 
and increased their SOC by around $45 \%$ of the battery's capacity per charge.

Table 1. Average driving and charging metrics of vehicles grouped by the percent of charges performed away from home.

\begin{tabular}{|c|c|c|c|c|}
\hline $\begin{array}{l}\% \text { of Charging Away } \\
\text { from Home }\end{array}$ & $0 \%$ & $\begin{array}{l}>0 \text { to } \\
30 \%\end{array}$ & $\begin{array}{l}>30 \text { to } \\
60 \%\end{array}$ & $>60 \%$ \\
\hline Vehicles (\% of total) & $94(5 \%)$ & $\begin{array}{l}1,520 \\
(81 \%)\end{array}$ & $\begin{array}{c}233 \\
(13 \%)\end{array}$ & $20(1 \%)$ \\
\hline $\begin{array}{l}\text { Percent of All Away- } \\
\text { from-Home Charging } \\
\text { Events }\end{array}$ & - & $44 \%$ & $51 \%$ & $5 \%$ \\
\hline $\begin{array}{c}\text { Home Overnight } \\
\text { Charges Per Day } \\
\text { Driven }\end{array}$ & 0.9 & 0.9 & 0.9 & 0.3 \\
\hline $\begin{array}{l}\text { Home Overnight } \\
\text { SOC Increase Per } \\
\text { Charge }\end{array}$ & $64 \%$ & $65 \%$ & $68 \%$ & $56 \%$ \\
\hline $\begin{array}{c}\text { Home Daytime } \\
\text { Charges Per Day } \\
\text { Driven }\end{array}$ & 0.3 & 0.4 & 0.3 & 0.1 \\
\hline $\begin{array}{l}\text { Home Daytime SOC } \\
\text { Increase Per Charge }\end{array}$ & $32 \%$ & $33 \%$ & $34 \%$ & $33 \%$ \\
\hline $\begin{array}{l}\text { Away-from-Home } \\
\text { Overnight Charges } \\
\text { Per Day Driven }\end{array}$ & - & 0.01 & 0.03 & 0.02 \\
\hline $\begin{array}{l}\text { Away-from-Home } \\
\text { Overnight SOC } \\
\text { Increase Per Charge }\end{array}$ & - & $72 \%$ & $68 \%$ & $67 \%$ \\
\hline $\begin{array}{c}\text { Away-from-home } \\
\text { Daytime Charges Per } \\
\text { Day Driven }\end{array}$ & - & 0.1 & 0.8 & 1.0 \\
\hline $\begin{array}{c}\text { Away-from-Home } \\
\text { Daytime SOC } \\
\text { Increase Per Charge }\end{array}$ & - & $40 \%$ & $47 \%$ & $44 \%$ \\
\hline $\begin{array}{l}\text { Total Charge Events } \\
\text { Per Day Driven }\end{array}$ & 1.2 & 1.4 & 2.0 & 1.4 \\
\hline $\begin{array}{l}\text { Total SOC Increase } \\
\text { from Charging Per } \\
\text { Day }\end{array}$ & $67 \%$ & $78 \%$ & $108 \%$ & $64 \%$ \\
\hline $\begin{array}{l}\text { Average Miles Per } \\
\text { Day Driven }\end{array}$ & 31.5 & 39.0 & 50.3 & 33.9 \\
\hline $\begin{array}{l}\text { Average EV Miles } \\
\text { Per Day Driven }\end{array}$ & 24.9 & 28.7 & 40.3 & 25.7 \\
\hline $\begin{array}{l}\text { Percent of Miles } \\
\text { Driven in EV Mode }\end{array}$ & $79 \%$ & $74 \%$ & $80 \%$ & $76 \%$ \\
\hline
\end{tabular}

The group with 30 to $60 \%$ of their charges away from home utilized home charging more than once per day and supplemented that charging with nearly one away-fromhome charge per day for a total daily SOC increase of $108 \%$. This charging allowed the vehicles in that group to drive more than 40 miles in EV mode per day, which is $60 \%$ farther than the vehicles that never charged away from home. All of the four groups were able to drive a significant portion of their miles in EV mode, with percentages ranging from 74 to $80 \%$.

Across all of the away-from-home charging frequency groups, vehicles averaged 74 to $80 \%$ of their distance driven in EV mode. Overall average charging frequency increased as average daily distance driven increased, suggesting that drivers changed their charging behavior in order to extend EV mode operation.

\section{About The EV Project}

The EV Project was the largest plug-in electric vehicle infrastructure demonstration project in the world, equally funded by the United States Department of Energy (DOE) through the American Recovery and Reinvestment Act and private sector partners. The EV Project deployed over 12,000 AC Level 2 charging stations for residential and commercial use, as well as over 100 dual-port DC fast chargers, in 15 U.S. regions. Approximately 8,300 Nissan LEAFs $^{\text {TM }}$, Chevrolet Volts, and Smart ForTwo Electric Drive vehicles were enrolled in the project.

Project participants gave written consent for The EV Project researchers to collect and analyze data from their vehicles and/or charging units. Data collected from the vehicles and charging infrastructure represented almost 125 million miles of driving and 4 million charging events. The data collection phase of The EV Project ran from January 1, 2011, through December 31, 2013. Idaho National Laboratory is responsible for analyzing the data and publishing summary reports, technical papers, and lessons learned on vehicle and charging unit use.

\section{Company Profile}

Idaho National Laboratory is one of DOE's 10 multi-program national laboratories. The laboratory performs work in each of DOE's strategic goal areas: energy, national security, science, and the environment. Idaho National Laboratory is the nation's leading center for nuclear energy research and development. Day-to-day management and operation of the laboratory is the responsibility of Battelle Energy Alliance.

For more information, visit avt.inl.gov/evproject.shtml.

\section{References}

1. See "Where do Chevrolet Volt drivers in The EV Project charge when they have the opportunity to charge at work?" at http://avt.inl.gov/pdf/EVProj/ChargingLocationWorkplaceVoltsMar2014.pdf. 


\section{Appendix A}

Figure A1 shows the number of vehicles included in this study in each of the 18 metropolitan areas where Chevrolet Volts were enrolled in The EV Project. Note that Oregon includes the Corvallis, Eugene, Portland, and Salem metropolitan areas. Washington State includes the Seattle and Olympia metropolitan areas.

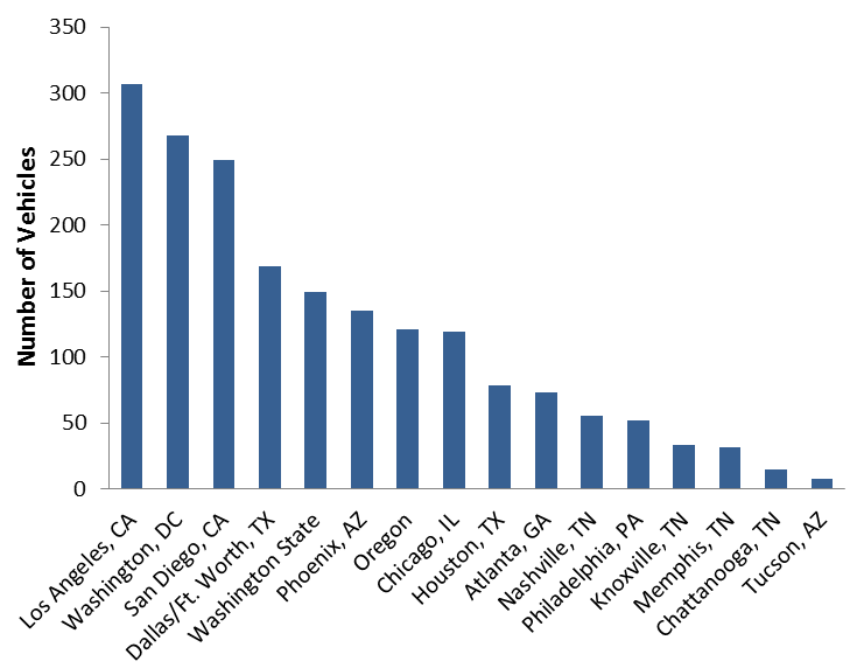

Figure A1. Number of The EV Project Chevrolet Volts by metropolitan area. 